\title{
Equal Distribution of Mating Type Alleles and the Presence of Strobilurin Resistance in Algerian Zymoseptoria tritici Field Populations
}

Hayet Meamiche Neddaf, Ecole Nationale Supérieure d'Agronomie, Laboratoire de Phytopathologie et de Biologie Moléculaire, El Harrach, Algérie; and Institut National de Recherche Agronomique d'Algérie, Division de Biotechnologies et d'Amélioration des Plantes, El Harrach, Algérie; Lamia Aouini, Wageningen University and Research Center, Wageningen, The Netherlands; Zouaoui Bouznad, Ecole Nationale Supérieure d'Agronomie, Laboratoire de Phytopathologie et de Biologie Moléculaire; and Gert H. J. Kema, Wageningen University and Research

\begin{abstract}
Zymoseptoria tritici, the causal agent of septoria tritici blotch, is an important wheat pathogen responsible for high yield losses worldwide. The assessment of the distribution of both mating type idiomorphs was studied in several wheat-growing areas in North Algeria. Both mating types occurred at all spatial scales tested and showed an equal frequency distribution at the country level, with $53 \%$ for Mat1-1 and $47 \%$ for Mat1-2. At finer scales, co-occurrence of both mating types was found in $38 \%$ of leaves analyzed and $44 \%$ of the studied lesions. Additionally,

efficacy reduction of strobilurin applications prompted us to study strobilurin resistance conferred by the G143A substitution in the mitochondrial cytochrome $b$ gene, which was found for the first time in six strains. The results suggest that the Algerian Z. tritici population undergoes frequent sexual reproduction mirrored by co-occurrence of both mating types, which likely will rapidly increase the fraction of strobilurinresistant isolates in the Algerian population, as has been shown in all other regions where strobilurin resistance surfaced.
\end{abstract}

The foliar wheat pathogen Zymoseptoria tritici (Quaedvlieg et al. 2011) causes septoria leaf blotch (STB), which is considered to be one of the most devastating wheat diseases worldwide (Fones and Gurr 2015; Torriani et al. 2015) and occurs every year throughout the major Algerian wheat-growing regions (Benbelkacem et al. 2011). Z. tritici is heterothallic with a bipolar mating system (Kema et al. 1996), undergoing both sexual and asexual reproduction. Sexual spores (ascospores) are airborne and can be dispersed over long distances, whereas asexual spores (pycnidiospores) are dispersed by rain splash over only limited distances (Chen and McDonald 1996; McDonald and Martinez 1990). Several secondary cycles of sexual reproduction occur within a single growing season (Hunter et al. 1999; Kema et al. 1996; Zhan et al. 2003), generating a high degree of genetic variation distributed even at small spatial scales (McDonald and Martinez 1990; Zhan et al. 2002, 2003). The mating type loci of $Z$. tritici have been intensively studied over the last decades (Kema et al. 1996; Siah et al. 2010b; Waalwijk et al. 2002; Zhan et al. 2002), showing their occurrence with equal distribution in most parts of the world as well as in some areas of Algeria (Abrinbana et al. 2010; Allioui et al. 2014; Boukef et al. 2012; Elbekali et al. 2012; Siah et al. 2010b; Zhan et al. 2002). Usually, an equal distribution of the Mat1-1 and Mat1-2 idiomorphs in natural field populations is consistent with frequent sexual cycles (Hunter et al. 1999; Zhan et al. 2002). Sexual reproduction generates new genotypes able to circumvent host resistance (Cowger and Mundt 2002) as well as adapt to other selective environments, such as those generated by fungicides. Disease control of STB is mainly based on chemical treatments (Fraaije et al. 2005) such as the chemical group of quinone outside inhibitors (QoI), also known as strobilurins. Due to their broad spectrum (Bartlett et al. 2002) and their additional favorable effects on plant physiology (Ruske et al. 2003), strobilurins were intensively used in STB management. The QoI act by binding to the quinoloxydizing (Qo) site of the mitochondrial cytochrome bc1 protein complex, thereby interfering with the mitochondrial respiration in the fungus (Bartlett et al. 2002). However, contrary to expectations, resistance to QoI rapidly surfaced in the United Kingdom in 2001 (Fraaije et al. 2003) and is conferred by a point mutation at codon 143 in the cytochrome

Corresponding author: G. H. J. Kema; E-mail: gert.kema@wur.nl.

Accepted for publication 5 October 2016.

() 2017 The American Phytopathological Society
$b(C y t b)$ gene, which led to an amino acid exchange from glycine to alanine at position 143 (G143A). This substitution in Cytb prevents binding of strobilurins to the Qo site and thereby restores mitochondrial respiration in the fungus (Fraaije et al. 2003; Gisi et al. 2002; Torriani et al. 2009). Intensive deployment of strobilurins over the last decade in Europe boosted the emergence and rapid spread of resistant strains among many countries (Drabešová et al. 2013; Fraaije et al. 2005; Gisi et al. 2005; Siah et al. 2010a; Torriani et al. 2009). In Maghreb countries, sterol demethylation inhibitors (DMI), also known as azoles, are widely used for STB control, and the use of strobilurins is fairly limited. Consequently, Z. tritici populations in these countries are supposed to be rather sensitive to strobilurins, supported by the absence of the G143A substitution in both Tunisia and Algeria (Allioui et al. 2013; Boukef et al. 2012; Somai-Jemmali et al. 2014; Stammler et al. 2012). However, recent studies reported the occurrence of QoI resistance in Z. tritici at low frequencies in Tunisia (Taher et al. 2014) and Morocco (Elbekali et al. 2011; Siah et al. 2014).

Here, we (i) determined the distribution of both $Z$. tritici mating types in Central and Eastern Algeria over different spatial scales and (ii) identified, for the first time, QoI resistance in these populations.

\section{Materials and Methods}

Sampling and strain isolation. A set of $213 \mathrm{Z}$. tritici isolates was obtained in 2013 and 2014 from naturally infected durum wheat fields (Triticum durum Desf.) in six different wheat-growing areas of Algeria (Alger, Blida, Tipaza, Constantine, Bouira, and Tipaza) (Fig. 1). Sampling was carried out from three durum wheat cultivars: Vitron, Chen'S, and Ammar 6 (Table 1). Leaves from different plants showing necrotic blotches with pycnidia were collected randomly from one or three fields at each location, and fragments of $5 \mathrm{~cm}$ were fixed to glass slides with sticky tape and kept under high-humidity conditions for $24 \mathrm{~h}$. Subsequently, chyrrhi from single pycnidia-one or more per lesion from one or more distinct lesions per leaf-were collected with a sterilized needle under a stereomicroscope and transferred to potato dextrose agar (PDA) supplemented with streptomycin (50 mg/liter). After colony appearance, pycnidiospores were spread onto fresh PDA petri plates and kept at room temperature for 4 days; and, finally, single colonies were transferred to fresh PDA plates and stored at $4^{\circ} \mathrm{C}$ until DNA extraction. In total, 213 isolates were collected, maintained, and analyzed (Table 1).

DNA extraction. Prior to genomic DNA extraction, $Z$. tritici isolates were grown on PDA for 5 days at $18^{\circ} \mathrm{C}$. Spore masses were subsequently scraped from the petri dishes and lyophilized in microtubes for $24 \mathrm{~h}$ (Epsilon 1-4/2-4 LCS plus; Martin Christ, Osterode am 
Harz, Germany). Two DNA extraction methods were used according to the pathogen population size. For the majority of isolates (192 isolates), DNA was isolated with a KingFisher DNA extraction robot (Thermo Electron Corporation, Breda, The Netherlands). Lyophilized spores were placed in microtubes containing a chrome/steel bead of $3.2 \mathrm{~mm}$ (Biospec Products, Bartlesville, OK) and were bead-beaten twice with a Tissue Lyser II (Qiagen, Hilden, Germany) for $20 \mathrm{~s}$ at $30 \mathrm{rpm} / \mathrm{s}$. Lysis buffer was added $(300 \mu \mathrm{l})$ along with $0.5 \mu \mathrm{l}$ of RNAse $(2 \mathrm{mg} / \mathrm{ml})$ and the microtube content was once more bead-beaten for $20 \mathrm{~s}$. After $30 \mathrm{~min}$ of incubation at $65^{\circ} \mathrm{C}$, the microtubes were centrifuged for $10 \mathrm{~min}$ at $6,000 \mathrm{rpm}$ (Sigma, Osterode am Harz, Germany). Clear supernatants ( $200 \mu \mathrm{l})$ were collected and used to fill deep well plates containing $520 \mu \mathrm{l}$ of binding buffer and $60 \mu \mathrm{l}$ of coated magnetic particles from the sbeadex Maxi Plant kit (LGCgroup, Berlin). During the process, the particle-bound DNA was washed twice with $400 \mu l$ of wash buffer and once with $400 \mu l$ of nuclease-free water. Finally, DNA was eluted in $120 \mu$ l of elution buffer and quantified with a spectrophotometer (ND-1000, NanoDrop Technologies, Wilmington, DE). For the remaining 20 isolates, the Wizard Magnetic DNA purification System for food Kit (Promega Corp., Madison, WI) was used according to the manufacturer's instructions, with a slight modification. Lyophilized spores $(50 \mathrm{mg}$ ) were placed in 2-ml tubes with a tungsten carbide bead and shaken in a Mini bead beater (Biospec Products) for $10 \mathrm{~s}$ at a maximum speed. Lysis buffer $(500 \mu \mathrm{l})$ was added and cells were disrupted by another round of bead-beating following the same protocol. The obtained DNA was resuspended in $100 \mu \mathrm{l}$ of nuclease-free water and quantified as mentioned above.

Polymerase chain reaction mating type and QoI resistance analyses. The mating type of each isolate was identified using a multiplex polymerase chain reaction (PCR) amplification of partial sequences from the two mating type idiomorphs, according to Waalwijk et al. (2002). The specific Mat1-1 and Mat1-2 primers (Table 2) generate amplicons of 340 and $660 \mathrm{bp}$ in length for Mat1-1 and Mat1-2, respectively. DNA of the Z. tritici Mat1-1 and Mat1-2 reference isolates IPO323 and IPO94269, respectively, were included as positive controls.

Sensitivity or resistance for the QoI fungicides among the Z. tritici isolates was determined following a mismatch amplification mutation assay, according to Ware (2006). The specific primers (Table 2) generate a 639-bp DNA fragment in sensitive isolates and a 302-bp DNA fragment in resistant isolates. DNA of the standard sensitive $Z$. tritici isolates IPO323 and IPO94269 were used as positive controls. PCRs for mating type analyses were carried out by adding $1 \mu l$ of genomic DNA (10 to $20 \mathrm{ng} / \mu \mathrm{l}), 5 \mu \mathrm{l}$ of $10 \times$ PCR buffer, $5 \mu \mathrm{l}(600 \mu \mathrm{M})$ of dNTP, $0.25 \mu \mathrm{l}$ (5 U/ $\mu \mathrm{l}$ ) of Taq DNA Polymerase (Ampli Taq Gold; Roche, Somerville,
MA), and $2.5 \mu \mathrm{l}(6 \mu \mathrm{M})$ of each primer to $50 \mu \mathrm{l}$ of nuclease free water. DNA samples were amplified using an MJ Research PT-100 thermocycler (Bio-Rad, Hercules, CA) programmed at $94^{\circ} \mathrm{C}$ for 2 min followed by 39 cycles of $94^{\circ} \mathrm{C}$ for $60 \mathrm{~s}, 68^{\circ} \mathrm{C}$ for $30 \mathrm{~s}$, and $72^{\circ} \mathrm{C}$ for $60 \mathrm{~s}$. The final extension was carried out at $72^{\circ} \mathrm{C}$ for $10 \mathrm{~min}$.

For QoI analyses, thermal cycling conditions started with initial denaturation at $94^{\circ} \mathrm{C}$ for $2 \mathrm{~min}$ followed by 39 cycles of $60 \mathrm{~s}$ at $94^{\circ} \mathrm{C}, 30 \mathrm{~s}$ at $55^{\circ} \mathrm{C}$ when primers pairs for sensitive isolates were used or $30 \mathrm{~s}$ at $60^{\circ} \mathrm{C}$ when primers pairs for resistant isolates were used, before $60 \mathrm{~s}$ at $72^{\circ} \mathrm{C}$ for extension for both sets of PCR. Final PCR cycles were followed by incubation for $10 \mathrm{~min}$ at $72^{\circ} \mathrm{C}$ and cooling-off at $10^{\circ} \mathrm{C}$. Amplification products were stained with GelRed, separated in $1 \%$ agarose gel, and visualized under UV-light.

Table 1. Origin of Zymoseptoria tritici isolates used in this study

\begin{tabular}{lrlr}
\hline Location & $\boldsymbol{N}^{\mathbf{a}}$ & Cultivar & Year of sampling \\
\hline Alger & 37 & Vitron & 2013 to 2014 \\
& 18 & Ammar & 2014 \\
Blida & 9 & Vitron & 2014 \\
& 43 & Chen'S & 2014 \\
Bouira & 13 & Waha & 2014 \\
Constantine & 50 & Vitron & 2014 \\
Médéa & 11 & Vitron & 2014 \\
Tipaza & 32 & Vitron & 2014 \\
Total & 213 & $\ldots$ & $\ldots$ \\
\hline
\end{tabular}

${ }^{a}$ Number of isolates.

Table 2. Primers used for Zymoseptoria tritici in this study

\begin{tabular}{ll}
\hline Primer & \multicolumn{1}{c}{ Sequence $\left(5^{\prime}\right.$ to 3 $^{\prime}$ ) } \\
\hline MAT1-1 F & CCGCTTTCTGGCTTCTTCGCACTG \\
MAT1-1 R & TGGACACCATGGTGAGAGAACCT \\
MAT1-2 F & GGCGCCTCCGAAGCAACT \\
MAT1-2 R & GATGCGGTTCTGGACTGGAG \\
StrobSNP2fwd & CTTATGGTCAAATGTCTTTATGATG \\
StrobSNP1rvs & GGTGACTCAACGTGATAGC \\
StrobSNPrcF7 & CAATAAGTTAGTTATAACTGTTGCGG \\
StrobSNPrcR1 & bTATGCATTATAACCCTAGCGT \\
\hline
\end{tabular}

a Waalwijk et al. (2002).

b Ware (2006).

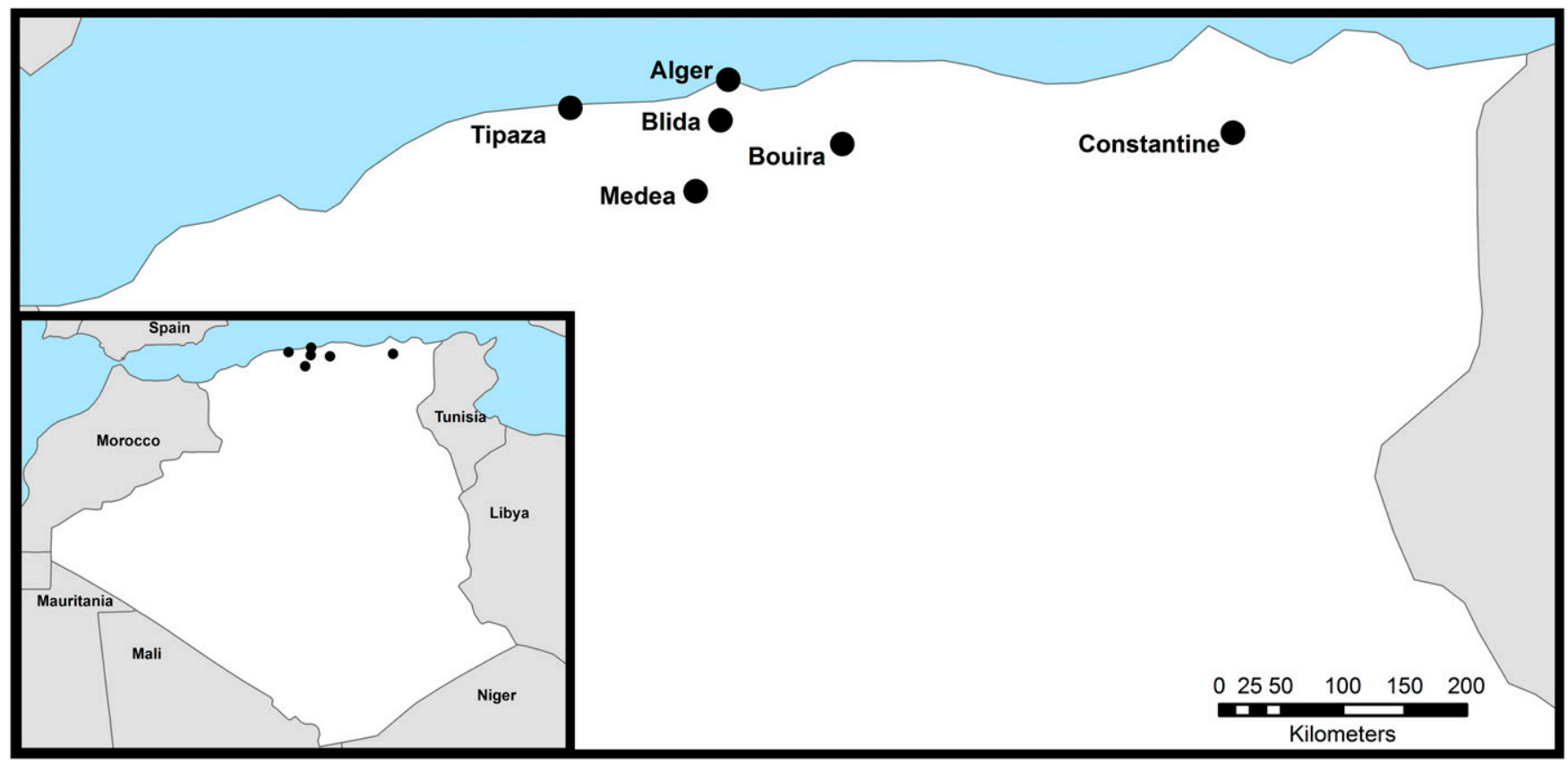

Fig. 1. Map displaying sampling locations of the Zymoseptoria tritici populations. 
Fungicide sensitivity bioassay. In order to validate the PCR analyses for QoI resistance, colony development of six isolates carrying the QoI-resistant allele and three isolates carrying the QoI-sensitive allele was compared on strobilurin-amended (azoxystrobin at $1 \mathrm{ppm}$; Amistar; Syngenta, Basel, Switzerland) PDA plates as described earlier (Ware 2006). Isolates $(5 \mu \mathrm{l}$ with a concentration of $4 \times$ $10^{5}$ spore $/ \mathrm{ml}$ ) were spotted on amended agar plates as well as regular PDA plates amended with $1 \%$ methanol as controls. All plates were replicated three times and incubated in the dark at $20^{\circ} \mathrm{C}$ for 10 days.

Data analyses. The mating type distributions were determined at different spatial scales: within lesions, within leaves, within fields, and within locations. To detect any significant deviation from the expected 1:1 ratio, frequencies of both mating types were analyzed at field and location level using the $\chi^{2}$ test at the significance level $P=0.05$, and the distributions between locations were tested using Pearson's $\chi^{2}$ test.

\section{Results}

Mating types determination. In total, 213 Z. tritici isolates were obtained (Table 1) and subsequently assayed for Mat1-1 and Mat1-2 frequencies. The mating-type-specific PCR generated a single amplicon of either 340 or $660 \mathrm{bp}$, corresponding with the Mat1-1 or Mat1-2 alleles, respectively, in 208 isolates (Fig. 2).

Macro- and microgeographical distribution of $Z$. tritici Mat alleles. Both mating types were found among all Z. tritici isolates that were isolated from the six sampled locations. Overall, the 208 tested isolates showed a 1:1 ratio as expected in random mating populations with 110 isolates (53\%) Mat1-1 and 98 Mat1-2 isolates (47\%).

The $\chi^{2}$ test analysis revealed no significant differences in the frequencies of the two mating types within and among locations (Table 3). Both mating types occurred at equal frequencies in each location, with an absolute equal distribution in Blida (Table 3). One to three fields per location were analyzed and tested for the mating type frequencies with a $\chi^{2}$ test and the results showed that field 2

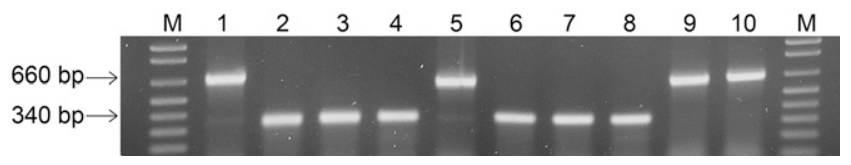

Fig. 2. Multiplex polymerase chain reaction for Mat1-1 or Mat1-2 mating type determinations in Algerian Zymoseptoria tritici isolates. Lanes 1 and 2: specific amplicons generated in the reference isolates IP094269 (660 bp, Mat1-2) and IPO323 (340 bp, Mat1-1); lanes 3 to 10: various explanatory field isolates from Alger, Blida, and Constantine; and lane M, 100-bp DNA ladder.

Table 3. Frequency distributions of Zymoseptoria tritici mating types within fields and among locations

\begin{tabular}{|c|c|c|c|c|c|c|}
\hline \multirow[b]{3}{*}{ Location } & \multirow[b]{3}{*}{ Field } & \multirow[b]{3}{*}{$N^{\mathrm{a}}$} & \multirow{2}{*}{\multicolumn{2}{|c|}{ Frequency }} & \multicolumn{2}{|c|}{$\chi^{2}$ Values (df) } \\
\hline & & & & & \multirow{2}{*}{$\begin{array}{l}\text { Within } \\
\text { fields }\end{array}$} & \multirow{2}{*}{$\begin{array}{c}\text { Among } \\
\text { locations }\end{array}$} \\
\hline & & & Mat1-1 & Mat1-2 & & \\
\hline \multirow[t]{3}{*}{$\overline{\text { Alger }}$} & 1 & 31 & 0.48 & 0.52 & $0.03(1)$ & $0.51(5)$ \\
\hline & 2 & 13 & 1.00 & 0.00 & $10.28 *(1)$ & $\ldots$ \\
\hline & 3 & 10 & 0.20 & 0.80 & $3.6(1)$ & $\ldots$ \\
\hline \multirow[t]{3}{*}{ Blida } & 1 & 15 & 0.53 & 0.47 & $0.06(1)$ & $\ldots$ \\
\hline & 2 & 15 & 0.40 & 0.60 & $0.6(1)$ & $\ldots$ \\
\hline & 3 & 22 & 0.55 & 0.45 & $0.18(1)$ & $\ldots$ \\
\hline \multirow[t]{3}{*}{ Constantine } & 1 & 10 & 1.00 & 0.00 & $10.00 *(1)$ & $\ldots$ \\
\hline & 2 & 10 & 0.70 & 0.30 & $1.6(1)$ & $\ldots$ \\
\hline & 3 & 28 & 0.29 & 0.71 & $5.14 *(1)$ & $\ldots$ \\
\hline \multirow[t]{2}{*}{ Tipaza } & 1 & 17 & 0.47 & 0.53 & $0.05(1)$ & $\ldots$ \\
\hline & 2 & 14 & 0.57 & 0.43 & $0.28(1)$ & $\ldots$ \\
\hline Bouira & 1 & 12 & 0.58 & 0.42 & $0.33(1)$ & $\ldots$ \\
\hline Médéa & 1 & 11 & 0.55 & 0.45 & $0.39(1)$ & $\ldots$ \\
\hline Total & 13 & 208 & 0.53 & 0.47 & $0.69(1)$ & $\ldots$ \\
\hline
\end{tabular}

a Number of isolates. from Alger and fields 1 and 3 from Constantine showed a significant deviation from a $1: 1$ ratio $\left(\chi^{2}\right.$ test, $\left.P=0.05\right)$. The former fields showed exclusively Mat1-1 strains.

Occurrence of the two mating types on the same leaf or within the same lesion was observed in each location tested, even in fields with a small sample sizes such as those from Bouira and Médéa (Tables 4 and 5). A fine spatial scale investigation on wheat leaves revealed the coexistence of both mating types in the same lesion in $44 \%$ (8 of 18) of the cases whereas, when multiple lesions on the same leaf were analyzed, both mating types were found in 38\% (10 of 26) of the leaves. Co-occurrence of both mating types with a 1:1 ratio was observed at either lesion and at each leaf scale.

Table 4. Distribution of Zymoseptoria tritici mating types among isolates from the same leaf

\begin{tabular}{|c|c|c|c|c|}
\hline Leaf number & Location & No. isolates & Mat1-1 & Mat1-2 \\
\hline 1 & Alger & 6 & 2 & 4 \\
\hline 2 & Alger & 7 & 3 & 4 \\
\hline 3 & Alger & 7 & 5 & 2 \\
\hline 4 & Alger & 8 & 2 & 4 \\
\hline 5 & Alger & 7 & 7 & 0 \\
\hline 6 & Alger & 6 & 6 & 0 \\
\hline 7 & Alger & 10 & 2 & 8 \\
\hline 8 & Blida & 11 & 11 & 0 \\
\hline 9 & Blida & 6 & 6 & 0 \\
\hline 10 & Blida & 6 & 4 & 2 \\
\hline 11 & Blida & 8 & 0 & 8 \\
\hline 12 & Blida & 15 & 2 & 13 \\
\hline 13 & Constantine & 8 & 8 & 0 \\
\hline 14 & Constantine & 9 & 6 & 3 \\
\hline 15 & Constantine & 11 & 0 & 11 \\
\hline 16 & Constantine & 6 & 3 & 3 \\
\hline 17 & Constantine & 11 & 5 & 6 \\
\hline 18 & Tipaza & 8 & 8 & 0 \\
\hline 19 & Tipaza & 7 & 0 & 7 \\
\hline 20 & Tipaza & 9 & 5 & 4 \\
\hline 21 & Tipaza & 7 & 3 & 4 \\
\hline 22 & Bouira & 3 & 3 & 0 \\
\hline 23 & Bouira & 7 & 3 & 4 \\
\hline 24 & Bouira & 2 & 1 & 1 \\
\hline 25 & Médéa & 5 & 3 & 2 \\
\hline 26 & Médéa & 6 & 3 & 3 \\
\hline Total & & 196 & 101 & 95 \\
\hline
\end{tabular}

Table 5. Distribution of Zymoseptoria tritici mating types among isolates from the same lesion

\begin{tabular}{llccc}
\hline Lesion number & Location & $N^{\mathbf{a}}$ & Mat1-1 & Mat1-2 \\
\hline 1 & Alger & 3 & 1 & 2 \\
2 & Alger & 3 & 3 & 0 \\
3 & Alger & 3 & 1 & 2 \\
4 & Alger & 4 & 4 & 0 \\
5 & Blida & 4 & 4 & 0 \\
6 & Blida & 4 & 1 & 3 \\
7 & Blida & 4 & 0 & 4 \\
8 & Blida & 5 & 1 & 4 \\
9 & Constantine & 5 & 5 & 0 \\
10 & Constantine & 4 & 1 & 3 \\
11 & Constantine & 5 & 5 & 0 \\
12 & Constantine & 3 & 2 & 1 \\
13 & Tipaza & 3 & 3 & 0 \\
14 & Tipaza & 3 & 0 & 3 \\
15 & Tipaza & 3 & 1 & 2 \\
16 & Tipaza & 4 & 2 & 2 \\
17 & Bouira & 2 & 1 & 1 \\
18 & Médéa & 4 & 2 & 2 \\
Total & .. & 66 & 37 & 29 \\
\hline
\end{tabular}

a Number of isolates. 
Screening for the G143A substitution. The presence of the G143A substitution conferring resistance in Z. tritici to QoI-based fungicides was investigated at six locations in Algeria by screening 213 isolates for the G143A mutation. We found six isolates from two different fields (Alger and Constantine) with a single 302-bp amplicon corresponding to the resistance allele A143, whereas the remaining isolates showed the 639-bp amplicon that is indicative of strobilurin sensitivity (Fig. 3). The G143A substitution occurred with a frequency of 0.02 among the locations tested and was found in field 1 in Alger with a frequency of 0.05 (3 of 54; 1 Mat1-1 and 2 Mat1-2) and with a frequency of 0.06 (3 of 48; 2 Mat1-1 and 1 Mat1-2) in field 2 in Constantine. Thus, in both locations, the G143A mutation occurred independently of the mating type of the Z. tritici isolates.

The sensitivity bioassay with azoxystrobin-amended PDA plates was performed with the six isolates carrying the G143A mutation and three wild-type isolates from the same fields. In vitro fungicide sensitivity bioassay results were consistent with the PCR assays, because the six isolates considered resistant to QoI formed colonies on the PDA plates amended with azoxystrobin at 1 ppm (Fig. 4), whereas the three isolates considered sensitive to QoI showed no mycelial growth at the same azoxystrobin concentration.

\section{Discussion}

The present study reveals that both $Z$. tritici mating types occur with equal frequency distributions at all scales studied. This suggests regular sexual reproduction cycles under Algerian conditions. Our results accord with previous reports from different countries all over the world (Siah et al. 2010b; Zhan et al. 2002), including countries with very different climatic conditions (Abrinbana et al. 2010; Allioui et al. 2014; Boukef et al. 2012; Elbekali et al. 2012), although the $Z$. tritici teleomorph was never reported in natural fields in Algeria. Evidence of the occurrence of sexual reproduction was pointed out by several authors in the past. Zhan et al. (2003), who analyzed a global collection from different continents, including 52 Algerian isolates, reported a high genotypic diversity, which highlighted a significant role of sexual recombination in shaping the $Z$. tritici population structure. Later, Midini and Hamza (2008) compared three populations from Canada, Tunisia, and Algeria and reported that the latter population showed the highest genetic diversity. Moreover, the assessment of virulence on a differential set that included bread and durum wheat cultivars allowed them to differentiate eight significantly different levels of pathogenicity, with four of those being unique to Algeria. Hence, these reports support our data and likely reflect the pathogens' adaptation potential to either environmental conditions or wheat species diversity in the country, as reported by McDonald and Linde (2002).

At the country level, the mating type ratio did not deviate significantly from the expected 1:1 = Mat1-1:Mat1-2 ratio, which was also reported for field populations in other Algerian regions (Allioui et al. 2014). However, the present study further supports the evidence of the occurrence of sexual recombination by showing that both mating types coexist with equal distributions regardless of climatic conditions, agricultural practices, and host distribution, similar to what was found in the French Z. tritici population, where the distribution of the mating types was also independent of geographical diversity (Siah et al. 2010b). Some individual fields-field 2 from Alger and fields 1 and 3 from Constantine-did not match 1:1 distributions for both mating type alleles but, at the location level, these frequencies were equal and, hence, such deviations are considered to result from sampling errors (Abrinbana et al. 2010; Elbekali et al. 2012). In our study, deviations may theoretically also result from an overrepresentation of clones because our data were not clone corrected due to the lower number of isolates per location. Indeed, our results confirmed earlier reports on the co-occurrence of both Z. tritici mating types at the leaf and lesion scales-even when the sample size was not large - in all locations sampled (Elbekali et al. 2012; El Chartouni et al. 2012; Linde et al. 2002; Siah et al. 2010b; Zhan et al. 2002). At the leaf scale, $62 \%$ of tested leaves were colonized by either Mat1-1 or Mat1-2 strains, which is not surprising, because most lesions are believed to be initiated by a single genotype (McDonald and Martinez 1990). As a consequence, successive leaf infections with pycnidiospores from the same haplotype could occur. Therefore, El Chartouni et al. (2012) suggested that genetic diversity at the leaf scale might be a good assessment of asexual reproduction. At the lesion scale, both mating types occurred in $44 \%$ of lesions when more than two isolates were assayed, similar to previous findings in other countries (Elbekali et al. 2012; El Chartouni et al. 2012). Given the known bipolar heterothallic mating system of $Z$. tritici (Kema et al. 1996), coexistence of isolates with the opposite mating type at small spatial scales facilitates mating, enabling rapid adaptation to environmental stresses (Linde et al. 2002).

The first QoI-resistant isolates of $Z$. tritici were detected in the United Kingdom in 2001 (Fraaije et al. 2005) and subsequently in five other European countries (Gisi et al. 2005). In the Maghreb countries, strobilurin deployment was limited compared with Europe, and recent investigations have reported the absence of the G143A substitution in Tunisia and Algeria (Allioui et al. 2013; Boukef et al. 2012; Somai-Jemmali et al. 2014; Stammler et al. 2012). The same results were initially reported in Morocco from a subset of 134 isolates collected in 2008 (El Bekali et al. 2011). However, the same study revealed, for the first time, the occurrence of QoI-resistant isolates in Morocco from a subset of 96 isolates collected in 2010. Similarly, Taher et al. (2014) detected three QoI-resistant isolates in Tunisia.

The collection of 213 field isolates of $Z$. tritici from six locations in Algeria was screened for QoI resistance and the G143A mutation was identified for the first time and confirmed with a fungicide sensitivity bioassay. Although just six mutants were found among these 213 isolates, the finding is significant because, thus far, all studies also in related fungi such as Pseudocercospora fijiensis in banana (Amil et al. 2007; Arango Isaza et al. 2016; Chin et al. 2001; Sierotzki et al. 2000) have shown that, once the mutation is selected, its frequency rapidly increases over time. Thus far, it was only observed in Alger and Constantine and none were found in Blida, Tipaza, Bouira, and Médéa, indicating that the QoI resistance likely only recently emerged in Algeria. However, we expect that it will spread rapidly over larger areas, because wind dispersal of ascospores (Torriani et al. 2009) combined with selection (Gisi et al. 2005) and stress-driven unavoidable paternal mating (Ware 2006) will dramatically increase the frequency of this newly emerged QoI resistance.

Our results showed the presence of QoI resistance in Algeria only in fields that were sprayed yearly with Amistar Pro (Azoxystrobin;

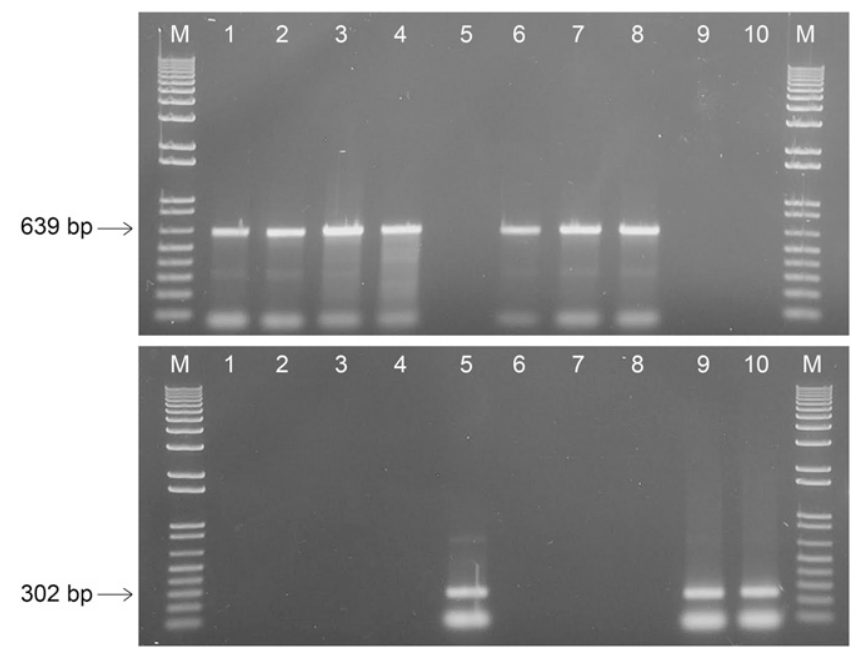

Fig. 3. Mismatch amplification mutation assay to determine the G143A mutation in the cytochrome $b$ gene in an Algerian Zymoseptoria tritici population. Lanes 1 and 2: sensitive control isolates IP094269 and IPO323; lanes 3, 4, 6, 7, and 8: sensitive isolates carrying the wild-type allele and showing an amplicon of $639 \mathrm{bp}$; lanes 5 , 9, and 10: resistant isolates with the G143A mutation indicated by the 302-bp amplicon; and lane M, 100-bp DNA ladder. 


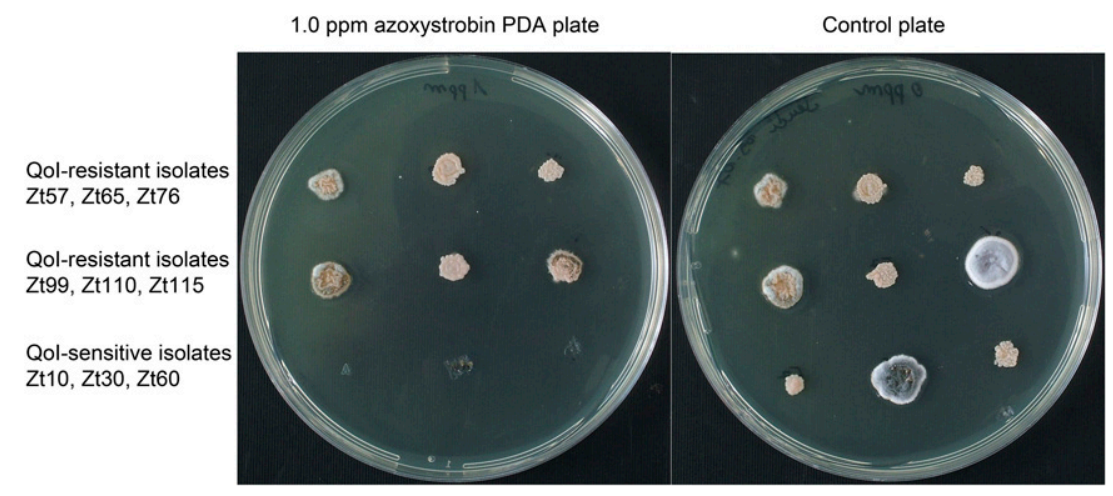

Fig. 4. Quinone outside inhibitor(Qol) fungicide sensitivity assay. Six Zymoseptoria tritici isolates carrying the G143A mutation grow normally on potato dextrose agar (PDA) plates amended with azoxystrobin at $1 \mathrm{ppm}$, whereas the three wild-type isolates were unable to develop colonies (left panel). PDA control plate amended with $1 \%$ methanol (right panel).

Syngenta). Information collected during this study showed that DMIs remain the main fungicide class for STB management in Algeria. Strobilurins are applied once a year, mainly for their greening effect, which contributes to a slight yield increase in some genotypes under water deficiency, as reported by Inagaki et al. (2009). Hence, a unique application each season was apparently enough for strobilurin resistance emergence. However, the low frequency of the G143A substitution reported in this study highlights the difference between European and North African populations of Z. tritici and provides a unique opportunity to monitor the expansion of QoIresistant strains in these and other locations.

Finally, the coexistence of the $Z$. tritici mating types across several spatial scales in Algeria opens up many possibilities for further studies, such as sexual crossings between isolates with known or unknown mating types to further the understanding of the epidemiology of $Z$. tritici in a wheat production system that is dominated by durum wheat under Mediterranean conditions.

\section{Acknowledgments}

This work was partially supported by the National Institute of Agricultural Research of Algeria. We thank M. Abdelguerfi, who hosts H. Meamiche Neddaf at the laboratory of molecular biology (Departement de Phytotechnie, ENSA, Alger); L. N. Salhi, for providing some reagents when needed; A. Benbelkacem for his support; A. M. Gohari for technical advice; and H. Benslimane for reviewing specific aspect of this project.

\section{Literature Cited}

Abrinbana, M., Mozafari, J., Shams-Bakhsh, M., and Mehrabi, R. 2010. Genetic structure of Mycosphaerella graminicola populations in Iran. Plant Pathol. 59:829-838.

Allioui, N., Siah, A., Brinis, L., Reignault, P., and Halama, P. 2013. Assessment of the cytochrome B substitution G143A in the Algerian population of Mycosphaerella graminicola. Commun. Agric. Appl. Biol. Sci. 78:613-616.

Allioui, N., Siah, A., Brinis, L., Reignault, P., and Halama, P. 2014. Mating type distribution provides evidence for sexual reproduction of Mycosphaerella graminicola in Algeria. Can. J. Plant Pathol. 36:475-481.

Amil, A. F., Heaney, S. P., Stanger, C., and Shaw, M. W. 2007. Dynamics of QoI sensitivity in Mycosphaerella fijiensis in Costa Rica during 2000 to 2003. Phytopathology 97:1451-1457.

Arango Isaza, R., Diaz-Trujillo, C., Dhillon, B., Aerts, A., Carlier, J., Crane, C. F., de Jong, T. V., de Vries, I., Dietrich, R., Farmer, A. D., Fortes Fereira, C., Garcia, S., Guzman, M., Hamelin, R. C., Lindquist, E. A., Mehrabi, R., Quiros, O., Schmutz, J., Shapiro, H., Reynolds, E., Scalliet, G., Souza, M., Jr., Stergiopoulos, I., Van der Lee, T. A. J., De Wit, P. J. G. M., Zapater, M.F., Zwiers, L.-H., Grigoriev, I. V., Goodwin, S. B., and Kema, G. H. J. 2016. Combatting a global threat to a clonal crop: Sequencing the banana black Sigatoka pathogen Pseudocercospora fijiensis (synonym Mycosphaerella fijiensis) reveals clues for disease control. PLoS Genet. 12:e1006365.

Bartlett, D. W., Clough, J. M., Godwin, J. R., Hall, A. A., Hamer, M., and Parr-Dobrzanski, B. 2002. The strobilurin fungicides. Pest Manage. Sci. 58: 649-662.

Benbelkacem, K., Bouznad, Z., Benslimane, H., and Salhi, L. N. 2011. Occurrence of Septoria leaf blotch in Algeria and assessment of wheat resistance. In: 8th Int. Symp. Mycosphaerella and Stagonospora Dis. Cereals, Mexico City.

Boukef, S., McDonald, B. A., Yahyaoui, A., Rezgui, S., and Brunner, P. C. 2012. Frequency of mutations associated with fungicide resistance and population structure of Mycosphaerella graminicola in Tunisia. Eur. J. Plant Pathol. 132:111-122.

Chen, R. S., and McDonald, B. A. 1996. Sexual reproduction plays a major role in the genetic structure of populations of the fungus Mycosphaerella graminicola, the Septoria tritici blotch fungus. Phytopathology 92:439-445.

Chin, K. M., Wirz, M., and Laird, D. 2001. Sensitivity of Mycosphaerella fijiensis from banana to trifloxystrobin. Plant Dis. 85:1264-1270.

Cowger, C., and Mundt, C. C. 2002. Agressiveness of Mycosphaerella graminicola isolates from susceptible and partially resistant wheat cultivars. Phytopathology 92:624-630.

Drabešová, J., Ryšánek, P., Brunner, P., McDonald, B. A., and Croll, D. 2013 Population genetic structure of Mycosphaerella graminicola and Quinone Outside Inhibitor (QoI) resistance in the Czech Republic. Eur. J. Plant Pathol. 135:211-224.

Elbekali, A. Y., Ramdani, A., El Chartouni, L., Tisserant, B., Deweer, C., FichterRoisin, C., Sanssene, J. B., Durand, R., Halama, P., and Reignault, P. 2012. First report of the mating types MAT1-1 and MAT1-2 of Mycosphaerella graminicola in Morocco. J. Plant Pathol. 94:243-247.

Elbekali, A. Y., Ramdani, A., Siah, A., Tisserant, B., Deweer, C., Hafidi, M., Reignault, P., and Halama, P. 2011. Detection of strobilurin-resistant isolates of Mycosphaerella graminicola in Morocco. Commun. Agric. Appl. Biol. Sci. 76:715-719.

El Chartouni, L., Tisserant, B., Siah, A., Duyme, F., Durand, R., Halama, P., and Reignault, P. 2012. Evolution of Mycosphaerella graminicola at the wheat leaf level and at the field level. Phytopathol. Mediterr. 2:332-339.

Fones, H., and Gurr, S. 2015. The impact of Septoria tritici Blotch disease on wheat: An EU perspective. Fungal Genet. Biol. 79:3-7.

Fraaije, B. A., Cools, H. J., Fontaine, J., Lovell, D. J., Motteram, J., and West, J. S. 2005 Role of ascospores in further spread of QoI-resistant cytochrome b alleles (G143A) in field populations of Mycosphaerella graminicola. Phytopathology 95:933-941.

Fraaije, B. A., Lucas, J. A., Clark, W. S., and Burnett, F. J. 2003. QoI resistance development in populations of cereal pathogens in the UK. In: Proc. BCPC Int. Congr. The British Crop Protection Council, Alton, Hampshire, UK. Crop Sci. Technol. 2:689-694.

Gisi, U., Pavic, L., Stanger, C., Hugelshofer, U., and Sierotzki, H. 2005. Dynamics of Mycosphaerella graminicola populations in response to selection by different fungicides. Pages 89-101 in: Modern fungicides and antifungal compounds IV. H. W. Dehne, U. Gisi, K. H. Kuck, P. E. Russell, and H. Lyr, eds. BCPC, Alton, UK.

Gisi, U., Sierotzki, H., Cook, A., and McCaffery, A. 2002. Mechanisms influencing the evolution of resistance to Qo inhibitor fungicides. Pest Manage. Sci. 58:859-867.

Hunter, R., Coker, R. R., and Royle, D. J. 1999. The teleomorph stage, Mycosphaerella graminicola, in epidemics of Septoria tritici blotch on winter wheat in UK. Plant Pathol. 48:51-57.

Inagaki, M., Mori, M., and Nachit, M. 2009. Effect of a strobilurin-class fungicide on water use in synthetic bread wheat genotypes grown under increasing water deficit conditions. Cereal Res. Comm. 37:513-519.

Kema, G. H. J., Verstappen, E. C. P., Todorova, M., and Waalwijk, C. 1996. Successful crosses and molecular tetrad and progeny analysis demonstrate heterothallism in Mycosphaerella graminicola. Curr. Genet. 30:251-258.

Linde, C. C., Zhan, J., and McDonald, B. A. 2002. Population structure of Mycosphaerella graminicola: From lesions to continents. Phytopathology 92: 946-955.

McDonald, B. A., and Linde, C. 2002. Pathogen population genetics, evolutionary potential, and durable resistance. Annu. Rev. Phytopathol. 40:349-379.

McDonald, B. A., and Martinez, J. P. 1990. DNA restriction fragment length polymorphisms among Mycosphaerella graminicola (anamorph Septoria tritici) isolates collected from a single wheat field. Phytopathology 80: 1368-1373. 
Medini, M., and Hamza, S. 2008. Pathotype and molecular characterization of Mycosphaerella graminicola isolates collected from Tunisia, Algeria, and Canada. J. Plant Pathol. 90:65-73.

Quaedvlieg, W., Kema, G. H. J., Groenwald, J., Verkley, G., Seifbarghi, S., Razavi, M., Gohari, A. M., Mehrabi, R., and Crous, P. 2011. Zymoseptoria gen. nov.: A new genus to accommodate Septoria-like species occurring on graminicolous hosts. Persoonia Mol. Phylogeny Evol. Fungi 26:57-69.

Ruske, R. E., Gooding, M. J., and Jones, S. A. 2003. The effects of triazole and strobilurin fungicide programmes on nitrogen uptake, partitioning, remobilization and grain $\mathrm{N}$ accumulation in winter wheat cultivars. J. Agric. Sci. 140:395-407.

Siah, A., Deweer, C., Morand, E., Reignault, P., and Halama, P. 2010a. Azoxystrobin resistance of French Mycosphaerella graminicola strains assessed by four in vitro bioassays and by screening of G143A substitution. Crop Prot. 29: 737-743.

Siah, A., Elbekali, A. Y., Ramdani, A., Reignault, P., Torriani, S. F. F., Brunner, P. C., and Halama, P. 2014. QoI resistance and mitochondrial genetic structure of Zymoseptoria tritici in Morocco. Plant Dis. 98:1138-1144.

Siah, A., Tisserant, B., El Chartouni, L., Duyme, F., Deweer, C., Fichter, C., Sanssené, J., Durand, R., Reignault, P., and Halama, P. 2010b. Mating type idiomorphs from French population of the wheat pathogen Mycosphaerella graminicola: Widespread equal distribution and low but distinct levels of molecular polymorphism. Fungal Biol. 114:980-990.

Sierotzki, H., Parisi, S., Steinfeld, U., Tenzer, I., Poirey, S., and Gisi, U. 2000. Mode of resistance to respiration inhibitors at the cytochrome bcl enzyme complex of Mycosphaerella fijiensis field isolates. Pest Manage. Sci. 56:833-841.

Somai-Jemmali, L., Selim, S., Siah, A., and Hamada, W. 2014. Fungicide sensitivity of Mycosphaerella graminicola Tunisian isolates: The importance of drug transporter genes in the process of fungicide tolerance. Phytopathol. Mediterr. 53:83-93.
Stammler, G., Taher, K., Koch, A., Haber, J., Liebmann, B., Bouagila, A., Yahyaoui, A., and Nasraoui, B. 2012. Sensitivity of Mycosphaerella graminicola isolates from Tunisia to epoxiconazole and pyraclostrobin. Crop Prot. 34: 32-36.

Taher, K., Graf, S., Fakhfakh, M. M., Salah, H. B. H., Yahyaoui, A., Rezgui, S., Nasraoui, B., and Stammler, G. 2014. Sensitivity of Zymoseptoria tritici isolates from Tunisia to Pyraclostrobin, Fluxapyroxad, Epoxiconazoles, Metconazole, Prochloraz and Tebuconazole. J. Phytopathol. 162:442-448.

Torriani, S. F. F., Bruner, P. C., McDonald, B. A., and Sierotzki, H. 2009. Qo resistance emerged independently at least 4 times in European populations of Mycosphaerella graminicola. Pest Manage. Sci. 65:155-162.

Torriani, S. F. F., Melichar, J. P. E., Mills, C., Pain, N., Sierotzki, H., and Courbot, M. 2015. Zymoseptoria tritici: A major threat to wheat production, integrated approaches to control. Fungal Genet. Biol. 79:8-12.

Waalwijk, C., Mendes, O., Verstappen, E. C. P., de Waard, M. A., and Kema, G. H J. 2002. Isolation and characterization of the mating type idiomorphs from the wheat Septoria leaf blotch fungus Mycosphaerella graminicola. Fungal Genet. Biol. 35:277-286

Ware, S. B. 2006. Aspects of sexual reproduction in Mycosphaerella species on wheat and barley: Genetic studies on specificity, mapping and fungicide resistance. Pages 101-122 in: Ph.D. thesis, Wageningen University, Wageningen, The Netherlands.

Zhan, J., Kema, G. H. J., Waalwijk, C., and McDonald, B. A. 2002. Distribution of mating type alleles in the wheat pathogen Mycosphaerella graminicola over spatial scales from lesions to continents. Fungal Genet. Biol. 36: 128-136.

Zhan, J., Pettway, R. E., and McDonald, B. A. 2003. The global genetic structure of the wheat pathogen Mycosphaerella graminicola is characterized by high nuclear diversity, low mitochondrial diversity, regular recombination, and gene flow. Fungal Genet. Biol. 38:286-297. 